\title{
HISTOPATHOLOGIC FINDINGS IN MULTICENTRIC PLACENTAL CHORANGIOMA WITH TROPHOBLASTIC PROLIFERATION IN A SHEEP
}

\author{
S. AZIZI ${ }^{1}$, R. KHEIRANDISH ${ }^{1}$, M. M. OLOUMI ${ }^{2} \&$ N. NADIMI ${ }^{3}$ \\ ${ }^{1}$ Department of Pathobiology, Faculty of Veterinary Medicine, Shahid Baho- \\ nar University of Kerman, Kerman, Iran; ${ }^{2}$ Department of Veterinary Surgery, \\ Faculty of Veterinary Medicine, Shahid Bahonar University of Kerman, \\ Kerman, Iran; ${ }^{3}$ Graduated of Veterinary Medicine Faculty, \\ Shahid Bahonar University of Kerman, Kerman, Iran
}

\begin{abstract}
Summary
Azizi, S., R. Kheirandish, M. M. Oloumi \& N. Nadimi, 2017. Histopathologic findings in multicentric placental chorangioma with trophoblastic proliferation in a sheep. Bulg. J. Vet. Med., 20, No 4, 400-407.

The present study described chorangioma in a sheep with clinical signs of dystocia. During surgery, foetus was not found and both of the uterine horns were distended with a lot of liquid. Multiple welldemarcated nodules of firm consistency, yellow-tan colour and $2.5-4 \mathrm{~cm}$ diameter were projected from the cotyledons into the lumens. Histopathologically, the nodules showed expanded chorionic villi composed of proliferated blood vessels in a variable amount of loose perivascular stroma. Syncytial trophoblast cells with hyperchromatic nucleus were dispersed in the tumour's parenchyma. Based on pathologic characteristics and according to the abundant vascular proliferation and nodular form, a neoplastic lesion named chorangioma was diagnosed. To the author's knowledge, it is the first report of chorangioma in sheep.
\end{abstract}

Key words: chorangioma, histopathology, sheep

Chorangioma, also referred to the placental haemangioma, is a benign tumour that originates from the primitive angioblastic tissue of the placenta (Lifschitz-Mercer et al., 1989). It is characterised with abundant vascular proliferation supported by villous stroma. In humans, the prevalence rate of chorangioma is estimated about $1 \%$ of placentas (Benirschke et al., 2006).
Maternal age increases the occurrence of this tumour. Chorangiomas are reported often in women more than 30 years old with primipara and twin pregnancies (Guschmann et al., 2003). Some complications in foetus or pregnant patients may be associated with this tumour. Polyhydramnia, preterm delivery and increased toxaemia may occur in pregnant patients 
(Bashiri et al., 1998; Taori et al., 2008). The foetus could be affected by nonimmune hydrops, cardiomegaly, congestive cardiac failure, circulatory disturbances (anaemia, thrombocytopenia, consumptive coagulopathy) and growth defects (prematurity, growth retardation) (Demiriz et al., 1997; Sepulveda et al., 2000; Batukan et al., 2001).

In humans, placental tumours occur frequently but in animals, few reports of placental tumours are available (Karlson \& Kelly, 1941; Corcoran \& Murphy, 1965; Kirkbride et al., 1973). The present study describes a rare case of chorangioma with trophoblastic proliferation in a sheep. To the author's knowledge, it is the first report in veterinary medicine.

A 3.5-year-old sheep, with distended abdomen and severe straining, was referred to the Veterinary Teaching Hospital, Shahid Bahonar University of Kerman. The animal was submitted to the Department of Surgery with the impression of pregnancy term, according to the date of mating as declared by the owner. In the obstetric examination, the cervix was found closed. The vital parameters were in the normal range. A survey laparotomy was designed from the left paralumbar fossa.

The animal was positioned in the right lateral recumbency and left low flank prepared for surgery. Inverted L local block was performed for analgesia with $1 \%$ lidocaine $\left(1 \mathrm{~mL} / \mathrm{cm}^{2}\right)$. Following approach to the uterus, foetus was not observed. Both of the uterine horns were distended by a large volume of liquid. Multiple translucent cysts of different sizes were notable on the endometrial surface of uterine horns (Fig. 1). Under every cyst, a well-demarcated nodule, $2.5-4 \mathrm{~cm}$ in diameter, was present. These nodules had firm consistency and yellow-tan colour. On their cut surface, red-brown foci were visible (Fig. 2). The sheep survived after the surgery.

Some tissue samples $\left(1 \mathrm{~cm}^{3}\right.$ thickness $)$ were taken from the nodules, fixed in $10 \%$ neutral-buffered formalin and then, processed according to the standard procedure.

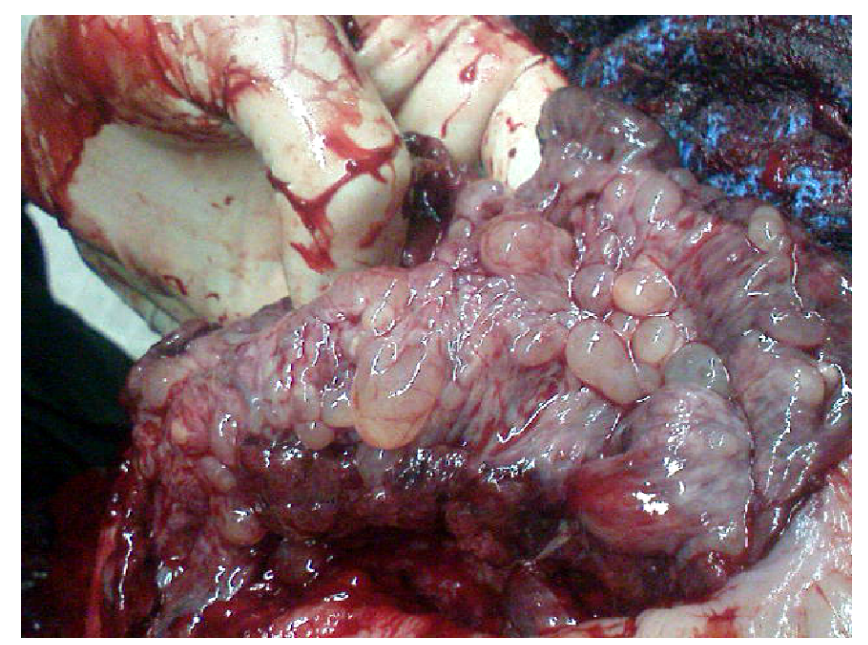

Fig. 1. Multiple translucent cysts in different sizes are visible on the endometrial surface of uterine horn. 
Histopathologic findings in multicentric placental chorangioma with trophoblastic proliferation ...

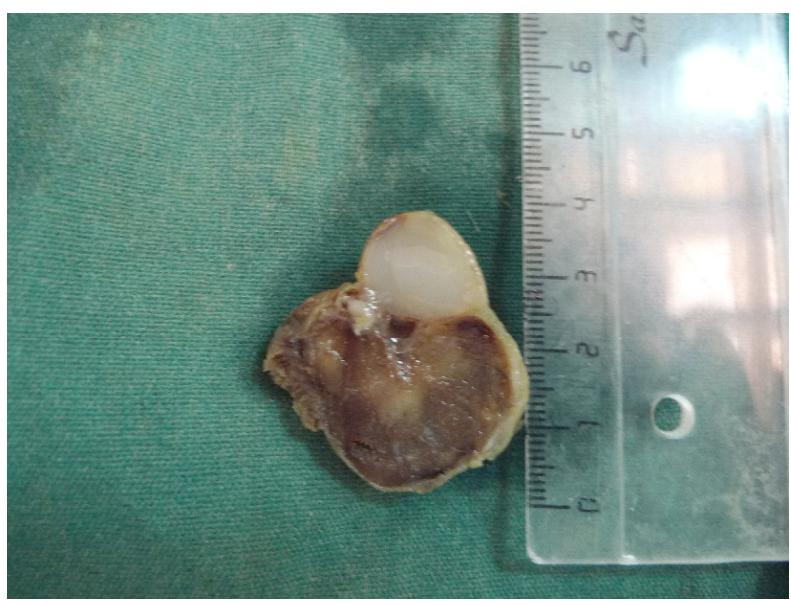

Fig. 2. Gross appearance of chorangioma as a well-demarcated nodule of firm consistency and yellow-tan colour.

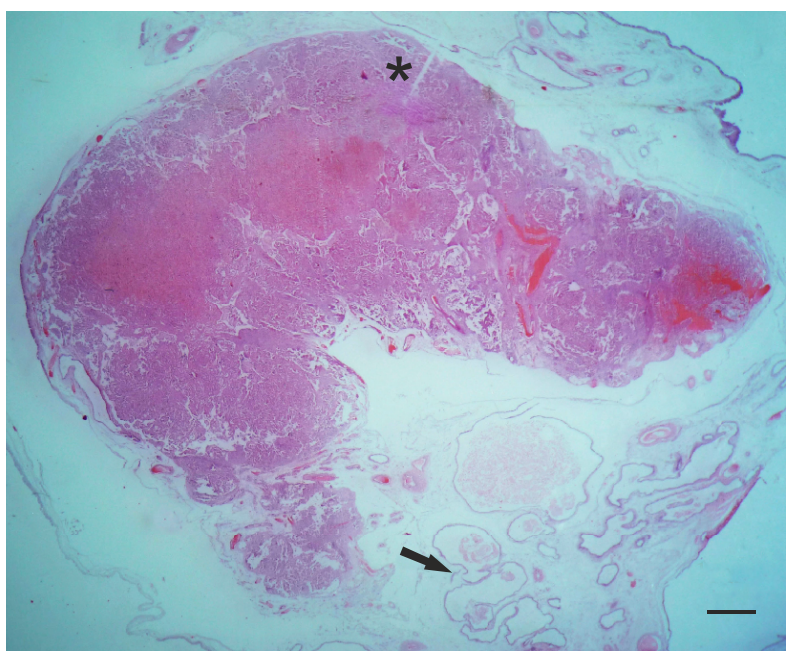

Fig. 3. Cystic uterine glands (arrow) and placental chorangioma mass as a haemangiomatous lesion (asterisk) (HE, Bar=1 mm).

Sections ( $5 \mu \mathrm{m}$ thickness) were stained with haematoxylin-eosin (HE) and studied by light microscopy.

The histopathologic study identified two portions including haemangiomatous and cystic parts were visible for each nodule (Fig. 3). The haemangiomatous lesion was composed of expanded chorionic villi containing proliferated blood vessels that were surrounded by a loose stroma. The blood vessels had different calibers from capillaries to arterioles that some of them anastomosed together (Fig. 4). Amyloidlike materials (or hyalinisation) were deposited intervillously. Abundant syncytial trophoblast cells with hyperchromatic 
nuclei were dispersed in the tumoural parenchyma (Fig. 5). Microcalcified foci and necrotic changes were present in the stroma. Cellular atypia and polymorphism were not observed. The remaining glands of uterine tubes were dilated and cystic. According to the abundant vascular proliferation and the nodular appearance, a neoplastic lesion named chorangioma was diagnosed.

Foetus was not found in the uterine horns. It is supposed that it was absorbed or aborted before. Since removal of all the masses was not possible, some samples were taken and the uterine incision and the abdominal wall were closed routinely.

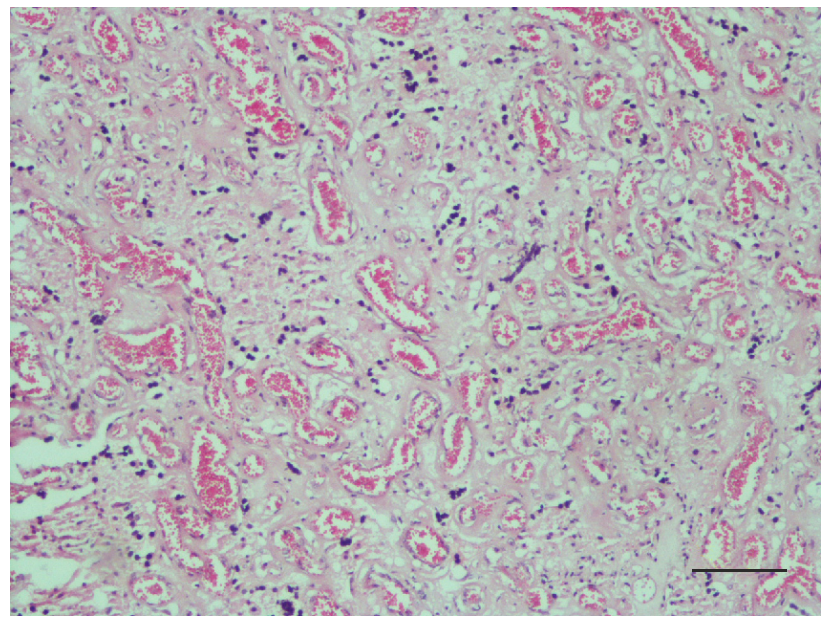

Fig. 4. Histopathologic features of placental chorangioma consisting of proliferated blood vessels surrounded by a loose stromal connective tissue $(\mathrm{HE}, \mathrm{Bar}=100 \mu \mathrm{m})$.

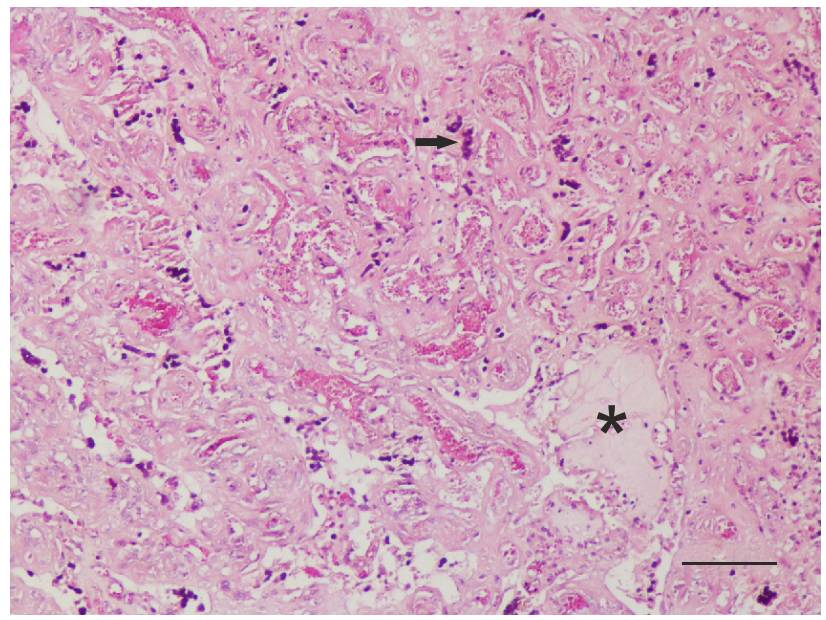

Fig. 5. Chorangioma with hyperchromatic syncytial trophoblastic cells (arrows) and amyloid-like materials in the stroma (asterisk) $(\mathrm{HE}, \mathrm{Bar}=10 \mu \mathrm{m})$. 
Histopathologic findings in multicentric placental chorangioma with trophoblastic proliferation ...

The animal was slaughtered by the owner the day after.

The placenta is responsible for transferring the immunity, and exchanging nutrients and waste products between mother and foetus. The placental structure is composed of the chorionic villus (villi and chorion). Vascular projections of foetal tissue (villi) are surrounded by the chorion. The chorion is made of two cellular layers including the outer syncytiotrophoblast (in direct contact with maternal blood) and inner cytotrophoblast (Power \& Kam, 2011). Placentitis is common but other placental disorders such as tumours are almost unique to the human and extremely rare in the animal species. Proliferative lesions of the placenta are classified into trophoblastic and nontrophoblastic tumours. Nontrophoblastic tumours comprise chorangiomas, teratomas, haemangiomas, and haematomas that originate from the blood vessels of the foetus but some researchers categorise it as a hamartoma containing primitive chorionic mesenchyme (Benirschke et al., 2006; Lez et al., 2010).

In animals, placental tumours are extremely rare. The present study described pathologic characteristics of multiple placental chorangioma with trophoblastic cells in a sheep. In this case, only placenta was present and a foetus was not found. In gross inspection, multiple nodules with firm texture and yellow-tan colour were observed in the uterine horns. Histopathologically, the nodules were composed of proliferated vascular channels placed in a loose perivascular stroma. Hyperchromatic trophoblastic cells were distributed in throughout the tumour, and sometimes formed syncytial knots. Hyalinisation, necrotic and calcified foci were the other findings. In the current case, our findings were consistent with previous studies in humans and animals (Kirkbride et al., 1973; Batukan et al., 2001; Kurman, 2002; Fox, 2003). We reported chorangioma associated with trophoblastic proliferation in a sheep. In this form, proliferation of placental villous vessels and trophoblastic cells are present that in the precious reports are used from term of chorangiocarcinoma by Jauniaux et al. (1988) and Trask et al. (1994). Khong (2000) stated that "chorangioma with trophoblastic proliferation" is more applicable to chorangiocarcinoma. Chorangiomas occur usually in the foetal side of placenta or in the umbilical cord as single to multiple nodules. Taori et al. (2008) described three types of chorangioma in humans including angiomatous, cellular, and degenerative with the predominance of the angiomatous chorangioma type. Lez et al. (2010) stated that chorangioma forms could be classified as haemangioma endotheliomatous, capillarious, cavernous and fibromatous form and that the most common is the capillarious one.

Zabka et al. (2006) reported a placental tumour in an East African bongo foetus. They presumed a placental stem cell tumor on the basis of histomorphology, histochemical and immunophenotypic results and comparing with 21 human cases of chorangioma. Kirkbride et al. (1973) described placental chorangioma associated with hemangioma in the skin and tongue of a bovine fetus. Placental mass was $13 \times 10 \times 8 \mathrm{~cm}$ and placed between the chorionic and allantoic epithelial layers of the placenta. Its cut surface had yellow color and were contained some dark red areas and necrotic centers. Microscopically, proliferated capillaries with large numbers of erythrocytes were present in a loose fibrous stroma and these findings were similar to the microscopic results of the present report. Other reports 
of placental tumours are angioma (Leaux, 1846) and myxoma (Morot, 1893) both of them cited by Drieux \& Thiéry (1948). Also, Karlson \& Kelly (1941) stated a choriohaemangioma in the placenta of a 2year-old Holstein cow with healthy parturition of a male calf.

Chorangioma may be misdiagnosed with infarction or intervillous thrombi. Small size chorangiomas are incidental findings and not clinically significant or detectable during gross inspection (Asadourian \& Taylor, 1968; Leonidas et al., 1975; Fox, 2003). Multicentric masses or those larger than $5 \mathrm{~cm}$ are usually associated with different complications in the mother or foetus (Asadourian \& Taylor, 1968; Leonidas et al., 1975). Chorangioma can be identified by sonography as hypoechoic protuberant mass on the foetal surface of the placenta. In addition, calcification and necrosis are occasionally visible (Eldar-Geva et al., 1988; Zalel et al., 2002).

Pathogenesis of chorangiomas is not entirely understood. It seems that hypoxic conditions induce vascular growth factors (Kirkpatrick et al., 2007). Schwartz (2001) described chorangioma as a compensatory response to improve foetal hypoxia. In an experimental study, proliferation of endothelial cell had occurred in the guinea pigs placentas following chronic hypoxia (Bacon et al., 1984). Rare recurrency of chorangioma suggests that some genetic or environmental risk factors such as smoking and air pollution contribute to formation of this proliferative lesion (Akbulut et al., 2009; Imdad et al., 2009). Dominant opinions believe that the chorangioma is a hamartomatous lesion rather than a true neoplasm (Al-Riyami et al., 2013).

It is probable that the incidence of placental tumours in animal species is higher than considered. To the author's know- ledge, it is the first report of chorangioma in veterinary medicine.

\section{REFERENCES}

Akbulut, M., H. C. Sorkun, F. Bir, A. Eralp \& E. Duzcan, 2009. Chorangiosis: the potential role of smoking and air pollution. $P a$ thology Research and Practice, 205, 7581.

Al-Riyami, N., R. Al-Hadabi, T. Al-Dughaishi \& M. Al-Riyami, 2013. Placental tumor: what could it be? Sultan Qaboos University Medical Journal, 13, E459-E462.

Asadourian, L.A. \& H. B. Taylor, 1968. Clinical significance of placental hemangiomas. Obstetrics and Gynecology, 31, 551-555.

Bashiri, A., E. Maymon, A. Wiznitzer, E. Maor \& M. Mazor, 1998. Chorangioma of the placenta in association with early severe polyhydramnios and elevated maternal serum HCG: A case report. European Journal of Obstetrics and Gynecology and Reproductive Biology, 79, 103-105.

Bacon, B. J., R. D. Gilbert, P. Kaufmann, A. D. Smith, F. T. Trevino, L. D. Longo, 1984. Placental anatomy and diffusing capacity in guinea pigs following long-term maternal hypoxia, Placenta, 5, 475-487.

Batukan, C., W. Holzgreve, E. Danzer, E. Bruder, I. Hosli, S. Tercanli, 2001. Large placental chorangioma as a cause of sudden intrauterine fetal death. A case report. Fetal Diagnosis and Therapy, 16, 394-397.

Benirschke, K. 1999. Recent trends in chorangiomas, especially those of multiple and recurrent chorangiomas. Pediatric and Developmental Pathology, 2, 264-269.

Benirschke, K., P. Kaufmann \& R. N. Baergen, 2006. Benign tumors and chorangiosis. In: Pathology of Human Placenta, $9^{\text {th }}$ edn, eds K. Benirschke \& P. Kaufmann, Springer, New York, pp. 863-876.

Corcoran, C. J. \& E. C. Murphy, 1965. Rare bovine placental tumor - a case report. The Veterinary Record, 77, 1234-1235. 
Histopathologic findings in multicentric placental chorangioma with trophoblastic proliferation ...

Drieux, H. \& G. Thiéry, 1948. Les tumeurs du placenta chez les animaux domestiques. Révue de pathologie comparée et d'hygiène générale, 48, 445-451.

Demiriz, M., Y. Tunca, A. Ozcan, B. Celasun \& R. Finci, 1997. Placental chorangioma associated with fetal cardiac complication. Acta Obstetricia et Gynecologica Scandinavica, 76, 708-709.

Eldar-Geva, T., D. Hochner-Celnikier, I. Ariel, M. Ron \& S. Yagel, 1988. Fetal high output cardiac failure and acute hydramnios caused by large placental chorangioma: A case report. British Journal of Obstetrics and Gynaecology, 95, 1200-1203.

Fox, H., 2003. Non-trophoblastic tumors of the placenta. In: Haines and Taylor $\mathrm{Ob}$ stetrical and Gynaecological Pathology, $5^{\text {th }}$ edn, ed H. Fox, Churchill Livingstone, Edinburgh, pp. 1450-1454.

Guschmann, M., W. Henrich, M. Entezami \& J. W. Dudenhausen, 2003. Chorangioma new insights into a well-known problem I. Results of a clinical and morphological study of 136 cases. Journal of Perinatal Medicine, 31, 163-169.

Imdad, A., L. Sheikh \& A. Malik, 2009. A large chorangioma causing intrauterine foetal demise. Journal of the Pakistan Medical Association, 59, 580-581.

Jauniaux, E., M. Zucker, S. Meuris, A. Verhest, P. Wilkin \& J. Hustin, 1988. Chorangiocarcinoma: An unusual tumor of the placenta. The missing link? Placenta, 9, 607-613.

Karlson, A. G. \& M. D. Kelly, 1941. Choriohemangioma of the bovine allantoischorion. Journal of the American Veterinary Medical Association, 99, 133-134.

Kirkbride, C. A., E. J. Bicknell \& M. G. Robl, 1973. Hemangiomas of a bovine fetus with a chorioangioma of the placenta. Veterinary Pathology, 10, 238-240.

Kirkpatrick, A. D., D. J. Podberesky, A. E. Gray \& J. H. McDermott, 2007. Best cases from the AFIP: Placental chorangioma. Radiographics, 27, 1187-1190.
Kurman, R. J., 2002. Blaustein's Pathology of the Female Genital Tract. $5^{\text {th }}$ edn, Springer, New York.

Khong, T. Y., 2000. Chorangioma with trophoblastic proliferation. Virchows Archiv, 436, 167-171.

Leonidas, J. C., E. C. Beatty \& R. T. Hall, 1975. Chorangioma of the placenta: A cause of cardiomegaly and heart failure in the new born American Journal of Roentgenology Radium Therapy Nuclear Medicine, 23, 703-707.

Lez, C., R. Fures, Z. Hrgovic, S. Belina, J. Fajdic \& K. Munstedt, 2010. Chorangioma placentae. Rare Tumors, 2, e67.

Lifschitz-Mercer, B., M. Fogel, I. Kushnir \& B. Czernobilsky, 1989. Chorangioma. A cytoskeletal profile. International Journal of Gynecological Pathology, 8, 349-356.

Power, I. \& P. Kam, 2011. Maternal and neonatal physiology. In: Principles of Physiology for the Anaesthetist. Arnold, London, pp. 345-364.

Sepulveda, W., G. Aviles, E. Carstens, E. Corral \& N. Perez, 2000. Prenatal diagnosis of solid placental masses: The value of color flow imaging. Ultrasound in Obstetrics and Gynecology, 16, 554-558.

Schwartz, D. A., 2001. Chorangiosis and its precursors: Underdiagnosed placental indicators of chronic fetal hypoxia. Obstetrical and Gynecolodical Survey, 56, 523525.

Taori, K., P. Patil, V. Attarde, A. Singh \& V. Rangankar, 2008. Chorangioma of placenta: sonographic features. Journal of Clinical Ultrasound, 36, 113-115.

Trask, C., J. M. Lage \& D. J. Roberts, 1994. A second case of "chorangiocarcinoma" presenting in a term asymptomatic twin pregnancy: choriocarcinoma in situ with associated villous vascular proliferation. International Journal of Gynecological Pathology, 13, 87-91.

Zabka, T. S., R. E. Papendick \& K. Benirschke, 2006. Placental tumor from an East 
African Bongo (Eurycerus isaaci) fetus. Veterinary Pathology, 43, 785-789.

Zalel, Y., B. Weisz, R. Gamzu, E. Schiff, B. Shalmon \& R. Achiron, 2002. Chorangiomas of the placenta: Sonographic and Doppler flow characteristics. Journal of Ultrasound in Medicine, 21, 909-913.

Paper received 12.01.2016; accepted for publication 26.02.2016

\section{Correspondence:}

Dr. Shahrzad Azizi

Department of Pathobiology,

Faculty of Veterinary Medicine,

Shahid Bahonar University of Kerman,

Kerman, Iran

e-mail: azizi.shahrzad@gmail.com 